\title{
Analysis of concrete-filled stainless steel tubular columns under combined fire and loading
}

\author{
Q. H. Tan ${ }^{a *}$, L. Gardner ${ }^{b}$, L. H. Han ${ }^{c}$ and D. Y. Song ${ }^{a}$ \\ ${ }^{a}$ Department of Civil Engineering, National University of Defense Technology, P. R. China \\ ${ }^{b}$ Department of Civil and Environmental Engineering, Imperial College London, UK \\ ${ }^{\mathrm{C}}$ Department of Civil Engineering, Tsinghua University, P. R. China \\ *corresponding author, e-mail address: tanqinghua@nudt.edu.cn
}

\begin{abstract}
In fire scenarios, concrete-filled stainless steel tubular (CFSST) columns undergo initial loading at ambient temperature, loading during the heating phase as the fire develops, loading during the cooling phase as the fire dies out and continual loading after the fire. CFSST columns can fail at different points during this process depending on the fire and loading parameters. In this paper, the failure modes and corresponding working mechanism of CFSST columns subjected to an entire loading and fire history are investigated. Sequentially coupled thermal-stress analyses in ABAQUS are employed to establish the temperature field and structural response of the columns. To improve the precision of the finite element (FE) model, the influence of moisture on the thermal conductivity and specific heat of concrete during both the heating and cooling phases is considered using subroutines. Existing fire and post-fire test data of CFSST columns are used to validate the FE models. Comparisons between predicted and test results confirm that the accuracy of the FE models is acceptable; the FE models are then extended to simulate a typical CFSST column subjected to entire loading and fire histories. The behaviour of the column is explained by analysis of the temperature distribution, load versus axial deformation curves and failure response.
\end{abstract}

Keywords: Concrete-filled stainless steel tubular (CFSST) columns; Heating; Cooling; Post-fire; Finite element (FE) models; Failure modes.

\section{Introduction}

Concrete-filled stainless steel tubular (CFSST) columns combine the advantages of concrete-filled steel tubular columns (CFST) and stainless steel, resulting in greater corrosion resistance, enhanced ductility and improved fire resistance [1-3]. Therefore, CFSST columns have great potential for application in engineering structures, especially in offshore structures. In the past ten years, there have been a number of research investigations into the static response of CFSST columns. Experimental and numerical studies on CFSST columns were conducted in [4-8] and the results show that CFSST columns generally have improved structural performance over conventional CFST columns.

Fire is recognized as a significant hazard during the life-cycle of a structure. Recently, research has been performed on the fire resistance of CFSST columns. Han et al. [2] tested five axially-loaded CFSST columns at elevated temperature, and parametric analyses were also conducted by finite element (FE) modelling. Tao and Ghannam [9] employed FE modelling to determine the temperature field in CFST and CFSST columns. Tao et al. [3] conducted an experimental and analytical investigation of CFSST columns in fire and after fire exposure. The test results showed that CFSST columns have both excellent fire resistance and post-fire residual strength.

Generally, a real fire consists of both heating and cooling. When subjected to fire, structural members undergo combined fire and loading, which includes several phases: the initial loading before the fire, loading during the heating phase as the fire develops, loading in 
the cooling phase as the fire dies out gradually and continual loading after fire. CFSST columns can fail at different points during this process. Some previous research has been conducted to investigate the combination of multi-phase fire and loading on CFST and steel reinforced concrete (SRC) structures. Yang et al. [10] developed a fiber model to consider the influence of cooling on the post-fire performance of CFST columns. Song et al. [11] developed an FE model to predict the load versus deformation relationships of CFST stub columns subjected to a combination of temperature and axial compression. Han et al. [12] developed an FE model to study the postfire performance of SRC columns subjected to both loading and fire phases. User-defined subroutines were adopted to automatically select the appropriate constitutive model during each of the four phases.

Limited research has however been published on the behaviour of CFSST columns subjected to entire loading and fire histories. To fill this research gap, this paper focuses on the influence of combined fire and loading on the response of CFSST columns by FE modelling. In this paper, an entire time $(t)$-load $(N)$ temperature $(T)$ path including ambient temperature loading, heating and cooling under constant load, and post-fire loading stages, which has been adopted in previous research [10-12], is employed. The following approach is taken in this paper:

(1) FE models are developed to investigate the performance of CFSST columns under the entire $t-N-T$ path.

(2) A series of fire resistance and post-fire tests on CFSST columns in the published literatures are used to systematically validate the FE models.

(3) Based on the validated FE models, the possible failure modes and corresponding response mechanism of a typical CFSST column during the entire loading and fire history are explained by analysis of temperature distribution, load versus axial deformation relations and load redistribution.

\section{Establishment of FE models}

The FE program ABAQUS [13] is adopted to simulate the behaviour of CFSST columns under the entire fire and load path. Sequential coupled thermal-stress analysis is used. Details of the temperature field and structural analysis models are introduced in this section.

\subsection{Temperature field analysis}

Tao and Ghannam [9] and Han et al. [2] developed an FE model to predict the temperature field in CFSST columns at elevated temperature. Song et al. [11] created FE models to replicate the temperature development in CFST columns in fire including both heating and cooling phases. In these FE models, the thermal properties of the steel and concrete in the cooling phase were assumed to be the same as those in the heating phase.

On the basis of the findings of the above research, the thermal properties of stainless steel, carbon steel and reinforcement proposed by Song et al. [11] and Guo [14], i.e., the thermal properties of stainless steel and carbon steel in EN 1993-1-2 [15], and reinforcement in EN 1994-1-2 [16] are used, respectively. For the convective coefficient and emissivity of the surfaces exposed to fire, $35\left(\mathrm{Wm}^{-2} \mathrm{~K}^{-1}\right)$ and 0.2 for stainless steel proposed in [17], and 25 $\left(\mathrm{Wm}^{-2} \mathrm{~K}^{-1}\right)$ and 0.7 for carbon steel as given in EN 1993-1-2 [15], are used, respectively. Since the interface between the outer tube and infilled concrete contains voids in-filled with water or steam, contact resistance occurs [18]. Ghojel [18], Tao and Ghannam [9] and Han et al. [2] have studied the contact conductance between the tube and concrete in CFST and CFSST columns through tests and FE modelling. The modelling recommendations of Han et al. [2] and Ghojel [18] are adopted.

It has been shown in previous research that the thermal conductivity of concrete in the heating phase is larger than that in the cooling phase, since in the cooling phase concrete is dry or has less adsorbed water [19]. Hence, this was reflected in the assignment of the thermal properties. For the thermal conductivity of the concrete during the heating and cooling phases, the models proposed in [14] were adopted. For the specific heat of the concrete during the heating phase, the model in EN 1994-1-2 [16] was used, but for that during the cooling phase, since concrete is dry or has less adsorbed water, the specific heat of concrete between $100{ }^{\circ} \mathrm{C}$ and $200{ }^{\circ} \mathrm{C}$ was assumed to be the same as that at $100^{\circ} \mathrm{C}$. 
A subroutine based on the temperature increment $\Delta T$ (" $\Delta T \geqslant 0$ " for the heating phase; " $\Delta T<0$ " for the cooling phase), was adopted to automatically choose the corresponding thermal models during the heating and cooling phases.

\subsection{Structural analysis}

(a) Material properties in different phases

The structural materials experience four temperature phases during the entire $t-N-T$ path, including ambient temperature, heating, cooling and post-fire phases. According to previous studies [10-12], different constitutive models for the steel and concrete corresponding to the four phases should be adopted due to the influence of the temperature changes. Elasticplastic models in Abaqus are used for stainless steel, carbon steel and rebars, while concrete damaged plasticity is adopted for the in-filled concrete. The details of the materials models at the different phases are introduced as follows.

(1) Ambient temperature and heating phases

The material properties at ambient temperature are a special case of those during the heating phase with the temperature $T=20$ ${ }^{\circ} \mathrm{C}$. The material properties of stainless steel and carbon steel at ambient temperature and in the heating phases are defined according to EN 1993-1-2 [15], while the material properties of the reinforcing bars are defined according to EN 1994-1-2 [16]. For the confined concrete, the material properties at ambient temperature and during the heating phases reported in [11] are used.

(2) Post-fire phase

The post-fire material models for carbon steel and reinforcing bars reported by Tao et al. [20], and austenitic stainless steel of grade 1.4301 reported by Wang et al. [21] are adopted herein.

A post-fire stress-strain model for concrete confined by a carbon steel tube was proposed by Song et al. [11]. The post-fire stress-strain model for concrete confined by a stainless steel tube is adopted as that in [11], but replacing the post-fire yield strength model of carbon steel in the post-fire confinement factor with that of stainless steel in [21].

(3) Cooling phase

The cooling phase is a transitional phase from the heating phase to the post-fire phase.
The mechanical properties of steel and concrete in the cooling phase are affected by the current and previous maximum temperature. For the stainless steel, carbon steel and reinforcing bars, the stress-strain relationships for the cooling phase are taken the same as those in the heating phase, but with yield strength, yield strain, ultimate strength and ultimate strain linearly interpolated between those in the heating and post-fire phases, as reported in [10]. For the confined concrete, the model in the cooling phase is essentially the same as that in the postfire phase, following that in $[10,11]$, but with the yield strength in the confinement factor replaced with that linearly interpolated between those in the heating phase and post-fire phase as described previously.

Since the structural materials have different stress-strain curves at the different phases, a subroutine is also needed to automatically choose the corresponding constitutive models for the four phases, as reported in [12].

\section{(b) Steel-concrete interfaces}

The surface-to-surface contact algorithm in ABAQUS is adopted to simulate the interaction between the stainless steel tube and the in-filled concrete. Hard contact in the normal and Coulomb friction in the tangential directions are defined. For the Coulomb friction model, a friction coefficient of 0.25 is adopted in this paper. For columns with reinforcing bars, tie constraints are employed between the reinforcing bars and the concrete.

\section{(c) Meshing and boundary conditions}

8-node brick elements (C3D8R) for the concrete and endplates, 4-node shell elements (S4) for the stainless steel tube, and 2-node truss elements (T3D2) for the reinforcing bars and stirrups are used to mesh the parts. Meshing and

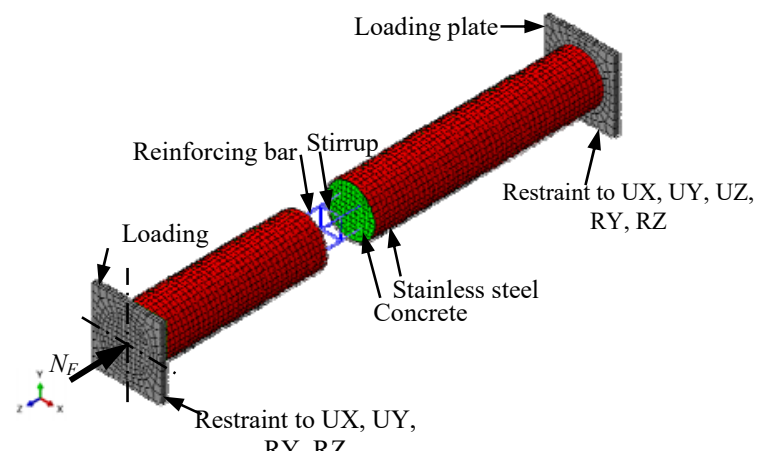

Fig. 1. Meshing and boundary conditions of the FE model. 
boundary conditions of the structural analysis model are shown in Fig. 1. In Fig. 1, the bottom of the column is fixed and the top of the column is restrained against displacements in the $\mathrm{X}$ and $\mathrm{Z}$ directions. Vertical axial load is applied at the top end in the $\mathrm{Y}$ direction.

\subsection{Validation of FE models for CFSST columns}

To validate the FE models, relevant test data on CFSST columns under fire reported in $[2,3]$ are utilized. Han et al. [2] tested five axiallyloaded specimens in fire, while Tao et al. [3] tested 6 specimens under fire and 6 specimens after fire with or without the presence of reinforcement. The test results, including the temperature-time curves, axial deformation development, fire resistance and post-fire loadbearing capacity, are compared with the corresponding predicted results herein.

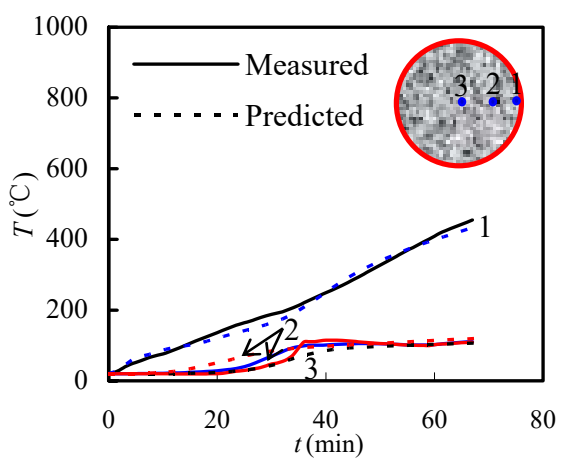

(a) $\mathrm{C} 300-0.45$ [2]

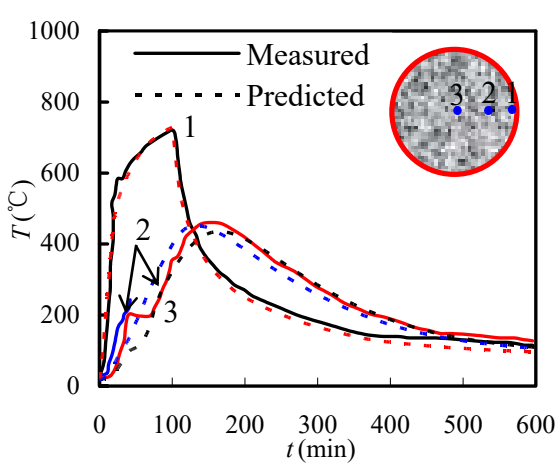

(b) CT05 [3]

Fig. 2. Typical temperature $(T)$ versus time $(t)$ curves of CFSST columns under fire.

Comparisons between typical measured and predicted temperature $(T)$ versus time $(t)$ curves of the CFSST columns are shown in Fig. 2. In general, there is reasonably good agreement between the FE predictions and the test results, which is also indicated in the comparisons made in $[2,3]$. The $T$ - $t$ curves in the concrete appear to show a platform at $100-200{ }^{\circ} \mathrm{C}$, which also occurred in the relevant fire tests. The predicted results show that the increase in the specific heat of the concrete between 100 ${ }^{\circ} \mathrm{C}$ and $200{ }^{\circ} \mathrm{C}$ can capture the characteristic of the water in the concrete evaporating at approximately $100{ }^{\circ} \mathrm{C}$. Additionally, the predicted temperature curves during the cooling phase also agree well with the measured results, as conductivity and specific heat of the concrete during cooling phase are lower than in the heating phase; this causes a relatively slower cooling rate than that without revision of the conductivity and specific heat.

The predicted axial deformation $(\Delta)$ versus time $(t)$ curves are compared with the measured results for fire and post-fire tests on CFSST columns in Figs. 3(a) and (b). The predicted $\Delta-t$ curves generally agree well with the test results. The predicted axial deformation, however, is generally smaller than the measured deformation in the expansion phase, particularly for Specimens CT05, CT08 and ST01 tested by Tao et al. [3]. This may be attributed to the discrepancy between the real thermal expansion coefficients of stainless steel and concrete and the values provided in EN 1993-1-2 [15] and EN 1994-1-2 [16].

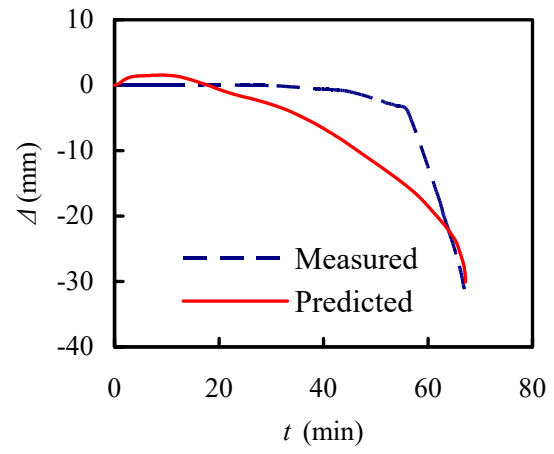

(a) $\mathrm{C} 300-0.45$ [2]

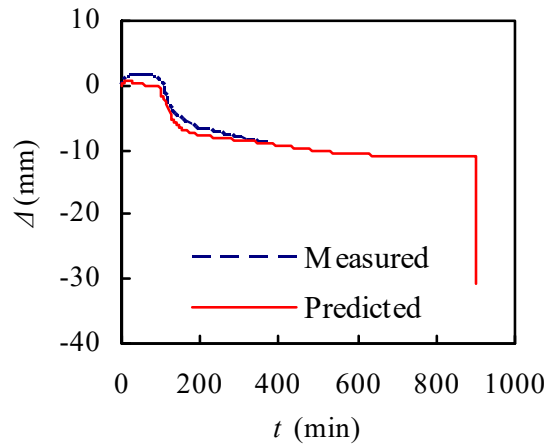

(b) CT05 [3]

Fig. 3. Typical axial deformation ( 4 ) versus time $(t)$ curves for CFSST columns. 
Fire resistance and residual load-bearing capacity are critical factors for the evaluation of CFSST columns. The disparity between the predicted and tested fire resistance are around $10 \%$, and the predicted fire resistance divided by test fire resistances have a mean ratio of 1.048 and a COV of 0.071. However, the disparity between the predicted and tested residual load-bearing capacity are between \pm $15 \%$.

From the above comparisons, it can be concluded that, in general, the accuracy of the FE modelling is acceptable. The FE modelling can now be extended to conduct full-range analyses of CFSST columns under fire conditions and after fire exposure.

\section{Failure mechanisms of CFSST columns under the full fire history}

In this section, the behaviour of a typical CFSST column is examined to explore the general response of this cross-section type in fire. The considered CFSST column has a circular cross-section $(800 \mathrm{~mm} \times 16 \mathrm{~mm})$ and a height $(H)$ of $6400 \mathrm{~mm}$. The cube strength and elastic modulus of the in-filled concrete are 60 $\mathrm{MPa}$ and $3.6 \times 10^{4} \mathrm{~N} / \mathrm{mm}^{2}$, respectively. The outer tube is formed from Grade S304 austenitic stainless steel, which is specified in CECS 410: 2015 [22] to have a $0.2 \%$ proof strength $\left(\sigma_{0.2}\right)$ and ultimate strength $\left(\sigma_{\mathrm{u}}\right)$ of 205 $\mathrm{MPa}$ and $515 \mathrm{MPa}$, respectively. For comparison purposes, pinned-pinned boundary conditions at the two ends are assumed. According to the FE models in Section 2, the axial load-bearing capacity and fire resistance of the prescribed column are $3.43 \times 10^{7} \mathrm{~N}$ and 65 mins, respectively.

The applied load ratio on the column is 0.4 , calculated as $n=N_{\mathrm{F}} / N_{\mathrm{u}}$, where $N_{\mathrm{F}}$ and $N_{\mathrm{u}}$ are the axial load applied to the column and the loadbearing capacity of the composite column at ambient temperature, respectively. The CFSST column is loaded with different heating times following the entire $t-N-T$ path described in previous research [10-12] and the fire, including the heating and cooling phases, follows the ISO 834 standard fire curves [23]. After a number of trials of different heating times, it is found that the studied column can fail during the different phases of the fire, i.e. in the heating, cooling or post-fire phases, and typical fire parameters for these cases are listed in Table 1, where $t_{\mathrm{R}}$ is the fire resistance of the CFSST column; $t_{\mathrm{h}}$ is the heating time of the fire curve, i.e. the ending time of the heating phase and the starting time of the cooling phase; $t_{\mathrm{p}}$ is the time for the temperature of the fire to decay to ambient temperature; $t_{\mathrm{d}}$ is the time for the temperature of the member to drop to ambient temperature, i.e. the ending of the cooling phase; $N_{\text {urp }}$ is the residual load-bearing capacity of the CFSST column after fire exposure; $\mathrm{H}, \mathrm{C}$ and $\mathrm{P}-$ $\mathrm{F}$ stand for the failure of CFSST column occurring in the heating, cooling and post-fire phases, respectively.

Table 1. Summary of CFSST column specimens.

\begin{tabular}{ccccccc}
\hline $\begin{array}{c}\text { Specimen } \\
\text { label }\end{array}$ & $\begin{array}{c}\boldsymbol{t}_{\mathbf{R}} \\
(\mathbf{m i n})\end{array}$ & $\begin{array}{c}\boldsymbol{t}_{\mathbf{h}} \\
(\mathbf{m i n})\end{array}$ & $\begin{array}{c}\boldsymbol{t}_{\mathbf{p}} \\
(\mathbf{m i n})\end{array}$ & $\begin{array}{c}\boldsymbol{t}_{\mathbf{d}} \\
(\mathbf{m i n})\end{array}$ & $\begin{array}{c}\boldsymbol{N}_{\text {urP }} \\
(\mathbf{k N})\end{array}$ & Notes \\
\hline Case 1 & 65 & 65 & - & - & - & $\mathrm{H}$ \\
Case 2 & 65 & 52 & 154 & 900 & - & $\mathrm{C}$ \\
Case 3 & 65 & 32.5 & 114 & 900 & 4983 & $\mathrm{P}-\mathrm{F}$ \\
\hline
\end{tabular}

\subsection{Temperature development in the heating and cooling phases}

The predicted temperatures $(T)$ as a function of fire exposure time $(t)$ for the CFSST columns under different conditions are shown in Fig. 4, where Point 1 represents the outer surface of stainless steel tube, and Points 2, 3 and 4 are the outer surface, mid-point of the radius and centre point of the core concrete, respectively.

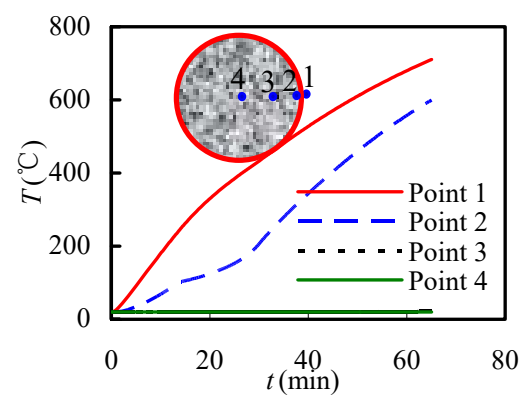

(a) For column failure duing the heating phase (Case 1)

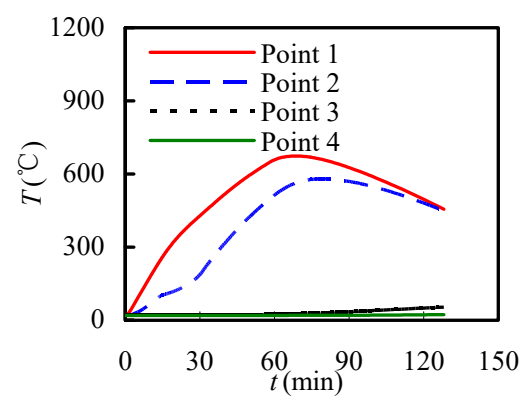

(b) For column failure duing the cooling phase (Case 2) 


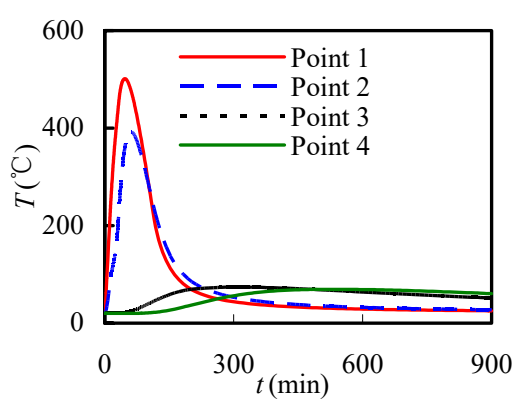

(c) For column failure doing the post-fire phase (Case 3)

Fig. 4. Temperature $(T)$ versus time $(t)$ curves of CFSST columns under different conditions.

For Points 1-4 during the heating phase, the temperature $(T)$ versus time $(t)$ curves show the same heating process as described in [2,3]. For Points 1-4 during the cooling phase, all 4 points reach their peak temperatures in the cooling phase. The further the location of the point to the fire-exposed surface, the more obvious the retard of the peak temperature. For example, as shown in Fig. 4 (c), Points 1 and 2 reach their peak temperature at about 47 mins and 61 mins, while the air temperature reaches its peak temperature at 32.5 mins. It is also shown that although the temperature of the outer part of the column is reducing, the temperature of the inner part is still increasing and the column may fail under this condition.

\subsection{Axial displacement versus time curves in all fire phases}

For the failure occurring in the heating phase (Case 1 in Table 1), the predicted axial displacement $(\Delta)$ verses time $(t)$ curve shown in Fig. 5(a), consists of four characteristic phases, i.e.

1) Ambient loading phase (o-a). During this phase, the initial load is applied to the CFSST column before exposure to fire, and the $\Delta-t$ relation is approximately linear.

2) Expansive phase (a-b). During this phase, the load on the CFSST column remains constant, and the environmental temperature increases. As the material temperature rises, material thermal expansion and degradation occur at the same time. However, in this phase, the effect of axial thermal expansion surpasses the effect of material degradation, and expansive deformation of the column is observed. When the effects of material expansion and degradation are balanced, the expansion displacement reaches its peak value at point $b$.

3) Softening phase (b-c). During this phase, the applied load remains constant and the temperature increases further. As the temperature of the fire increases, the contractive deformation induced by the material degradation becomes dominant. The axial deformation of the column changes from expansive to contractive.

4) Accelerated failure phase (c-d). In this phase, the second-order effects from the axial force and lateral deflection become dominant, and the axial deformation of the column increases rapidly; the column is deemed to have failed when the maximum axial contraction or the rate of contraction reach the failure criteria specified in ISO-834-1 [23].

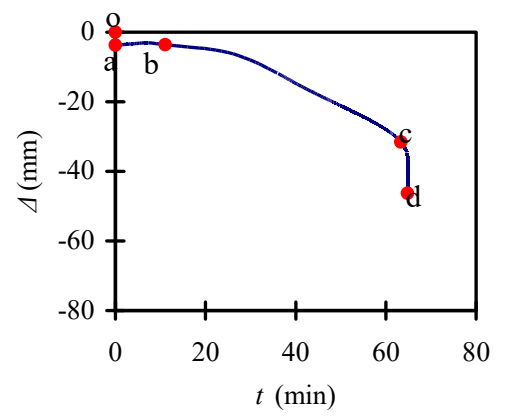

(a) For column failure duing the heating phase (Case 1)

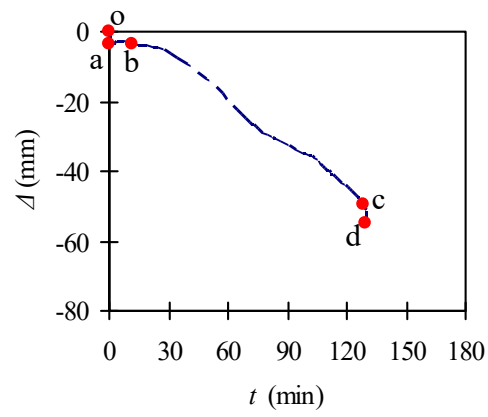

(b) For column failure duing the cooling phase (Case 2)

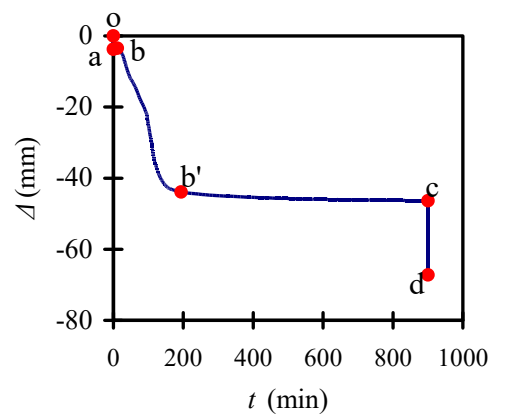

(c) For column failure doing the post-fire phase (Case 3)

Fig. 5. Typical axial deformation ( $(4)$ versus time $(t)$ curve of CFSST columns under different conditions. 
For the failure occurring in the cooling phase (Case 2 in Table 1), the predicted axial displacement $(\Delta)$ verses time $(t)$ curve shown in Fig. 5(b), displays a similar trend to that in Fig. 5(a) and also consists of four characteristic phases, i.e. the ambient loading phase (o-a), the expansive phase $(a-b)$, the softening phase (b-c) and the accelerated failure phase $(\mathrm{c}-\mathrm{d})$. The ambient loading phase and expansive phase of the curve in Fig. 5(b) are the same as those in Fig. 5(a), while the softening phase and accelerated failure phase of the curves are somewhat different. When the enviornmental temperature reaches the maximum temperature and then undergoes cooling, the temperature of the stainless steel tube and the outer part of infilled concrete decrease while the temperature of the inner part of in-filled concrete is still increasing, as shown in Fig. 4(b), i.e., the material performance of the stainless steel tube and the outer part of the in-filled concrete recovers during the cooling phase while that of the inner part of the in-filled concrete degrades. Therefore, in the softening phase, the contractive deformation induced by the material degradation becomes dominant and the axial deformation of the column changes from expansive to contractive. When the secondorder effect induced by the axial force is dominant, the axial deformation of the column increases rapidly and the column fails; in the meantime, the temperature of the stainless steel tube and the outer part of the in-filled concrete is still decreasing and the temperature of the inner part of the in-filled concrete is increasing.

For the failure occurring during the post-fire phase (Case 3 in Table 1), the predicted axial displacement $(\Delta)$ verses time $(t)$ curve shown in Fig. 5(c), consists of four characteristic phases, i.e., the ambient loading phase (o-a), the expansive phase $(a-b)$, the softening phase (b$\left.b^{\prime}-c\right)$ and the accelerated failure phase (c-d). The ambient loading and expansive phases of the curve in Fig. 5(c) are the same as those in Figs. 5(a) and (b), while the softening and accelerated failure phases of the curves are somewhat different. The recovery of the stainless steel tube and the outer part of the infilled concrete and the degradation of the inner part of the in-filled concrete results in contractive deformation of the column. When the fire exposure time is around 200 mins, the temperature of the materials decrease to around $100{ }^{\circ} \mathrm{C}$ and remains below $100^{\circ} \mathrm{C}$ until the end of the cooling phase $\left(b^{\prime}-c\right)$. Therefore, the curves of the softening phase from 200 mins to 900 mins show an approximate plateau as the mechanical performance of the stainless steel and concrete are essentially constant. When the cooling phase terminates, the prescribed column survives the fire including heating and cooling. The axial load is increased after the temperature of the prescribed column drops to ambient temperature, while the axial displacement increases rapidly until failure of the prescribed column.

\subsection{Failure modes}

The investigated CFSST column has a circular cross-section with a slenderness ratio of 32. All the circular columns under different fire conditions in Table 1 generally show compressive and flexural failure modes due to overall buckling accompanied by local buckling of the steel tube near the mid-height of the column, as shown in Fig. 6. However, some differences in the local buckling behaviour are observed when failure occurs in the different phases.

In order to explore the above phenomenon, the mid-span cross-section is isolated and the relative displacement between Point 1 at the inner face of the stainless steel tube and Point 2 at the outer surface of the concrete shown in Fig. 6, is extracted.

For failure during the heating phase, the relative displacement between Points 1 and 2 increases as the temperature rises with the differential expansion between the stainless steel tube and the concrete. The differential expansion arises due to the inconsistent temperature increment between Points 1 and 2 shown in Fig. 4(a) and the different thermal expansion coefficients between stainless steel and concrete. The column fails as the relative displacement between Points 1 and 2 reaches as high as 14.7 mm, as shown in Fig. 6(a).

For failure during the cooling phase, the relative displacement between Points 1 and 2 firstly increases during the heating phase reaching a maximum value $10.0 \mathrm{~mm}$; the tube then contracts as the temperature of the tube decreases in the cooling phase. The relative displacement decreases continuously until the column fails with the relative displacement at $3.7 \mathrm{~mm}$, as shown in Fig. 6(b). 
For the failure during the post-fire phase, the relative displacement between Points 1 and 2 firstly increases in the heating phase reaching a maximum value of $4.9 \mathrm{~mm}$. The tube contracts as the temperature of the tube decreases in the cooling phase, and the relative displacement reduces to $0.1 \mathrm{~mm}$ at the end of cooling phase. The axial load is increased in the post-fire phase with the severity of local buckling of the stainless steel tube increasing. The column fails at a relative displacement $1.2 \mathrm{~mm}$, as shown in Fig. 6(c).

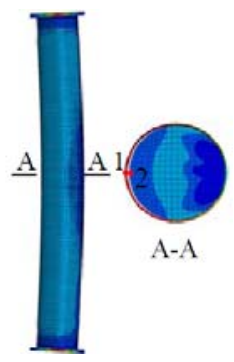

(a) Failure in the heating phase

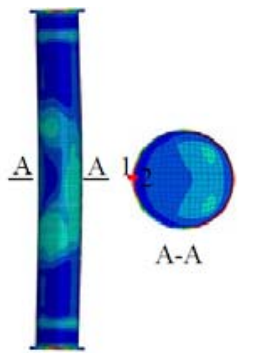

(b) Failure in the cooling phase

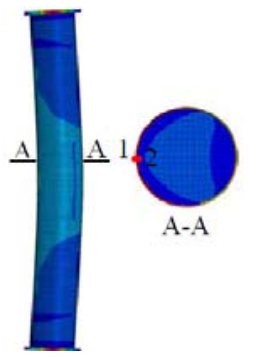

(c) Failure in the post-fire phase

Fig. 6. Failure modes of CFSST columns in different phases.

\section{Conclusions}

In this paper, FE models are established to simulate the behaviour of CFSST columns subjected to fire, considering the full heating and cooling history. The accuracy of the FE model is shown to be acceptable following comparisons with relevant test data. Based on the validated FE model, a slender CFSST column in fire is simulated and analysed. The results show that the severity of fire and load level have significant influence on the failure modes of a CFSST column, and the CFSST column may fail during the heating phase, cooling phase or post-fire phase displaying different levels of local buckling, coupled with overall flexural failure.

\section{Acknowledgements}

The research reported in the paper is part of the Project 51308539 supported by the National Natural Science Foundation of China. The financial support is highly appreciated.

\section{References}

[1]Gardner L. The use of stainless steel in structures. Progress in Structural Engineering and Materials 2005; 7: 45-55.

[2]Han LH, Chen F, Liao F Y, Tao Z, Uy B. Fire performance of concrete filled stainless steel tubular columns. Engineering Structures 2013; 56: 165-181.

[3]Tao Z, Mohamed G, Song TY, Han LH. Experimental and numerical investigation of concrete-filled stainless steel columns exposed to fire. Journal of Constructional Steel Research 2016; 118: 120-134.

[4]Young B, Ellobody E. Experimental investigation of concrete-filled cold-formed high strength stainless steel tube columns. Journal of Constructional Steel Research 2006; 62: 484492.

[5]Lam, D., and Gardner, L. Structural design of stainless steel concrete filled columns. Journal of Constructional Steel Research 2008, 64, 12751282.

[6]Tao Z, Uy B, Liao FY, Han LH. Nonlinear analysis of concrete-filled square stainless steel stub columns under axial compression. Journal of Constructional Steel Research 2010; 67: 17191732.

[7]Dabaon MA, El-Khoriby S, El-Boghdadi MH, Hassanein MF. Confinement effect of stiffened and unstiffened concrete-filled stainless steel tubular stub columns. Journal of Constructional Steel Research 2009; 65: 1846-1854.

[8]Hassanein MF. Numerical modelling of concretefilled lean duplex slender stainless steel tubular stub columns. Journal of Constructional Steel Research 2010; 66: 1057-1068.

[9] Tao Z, Mohamed G. Heat transfer in concretefilled carbon and stainless steel tubes exposed to fire. Fire Safety Journal 2013; 161, 1-11.

[10]Yang H, Han LH, Wang YC. Effects of heating and loading histories on post fire cooling behaviour of concrete filled steel tubular 
columns. Journal of Constructional Steel Research 2008; 64(5): 556-570.

[11]Song T Y, Han LH, Yu HX. Concrete filled steel tube stub columns under combined temperature and loading. Journal of Constructional Steel Research 2010; 66(3): 369384.

[12]Han LH, Zhou K, Tan QH, Song TY. Performance of Steel Reinforced Concrete (SRC) column after exposure to fire: FEA model and experiments. Journal of Structural Engineering ASCE 2016; 142(4): 04016055.

[13]ABAQUS. ABAQUS/Standard Version 6.14 User's Manual: Volumes I-III. Dassault Systèmes Simulia Corp, 2014, Rhode Island, USA.

[14]Guo S. Experimental and numerical study on restrained composite slab during heating and cooling. Journal of Constructional Steel Research 2012; 69: 95-105.

[15]EN 1993-1-2: 2005. Design of steel structuresPart 1-2: General rules-Structural fire design. European committee for standardization, 2005, Brussels.

[16]EN 1994-1-2: 2005. Design of composite steel and concrete structures-Part 1-2: General rules - Structural fire design. European committee for standardization, 2005, Brussels.
[17]Gardner L, Ng KT. Temperature development in structural stainless steel sections exposed to fire. Fire Safety Journal 2006; 41: 185-203.

[18]Ghojel J. Experimental and analytical technique for estimating interface thermal conductance in composite structural elements under simulated fire conditions. Experimental Thermal and Fluid Science 2004; 28(4): 347-54.

[19]Dos Santos WN. Experimental investigation of the effect of moisture on thermal conductivity and specific heat of porous ceramic materials. Journal of Materials Science 2000; 35 (16): 3977-3982.

[20]Tao Z, Wang XQ, Brian U. Stress-strain curves of structural and reinforcing steels after exposure to elevated temperatures. Journal of Materials in Civil Engineering ASCE 2013; 25(9): 1306-1316.

[21]Wang XQ, Tao Z, Song TY, Han LH. Stressstrain model of austenitic stainless steel after exposure to elevated temperatures. Journal of Constructional Steel Research 2014; 99: 129139.

[22]CECS 410: 2015. Technical specification for stainless steel structures. Beijing: China Planning Press, 2015. (In Chinese)

[23]ISO 834-1. Fire-resistance tests - elements of building construction - Part 1: General requirements. International Standard ISO 834, 1999, Geneva. 